\title{
A Solar Wall System Utilized in Rural Houses of Northeast China
}

\author{
Tiantian Zhang and Yufei Tan
}

\begin{abstract}
Resolving the conflict between the heating and ventilation in a rural house in winter becomes a major problem in improving the indoor thermal comfort and air quality. This paper proposes a solar wall system for rural buildings in cold regions for the purpose of increasing the indoor air temperature as well as improving the indoor air quality. Firstly, the structure and the operation modes of the system are introduced in detail. Then the methods of testing and instrument are detailed. Based on the test, the heating capacity of the solar wall system has been evaluated by investigating the temperature distributions of the solar walls and indoor spaces. Finally, the influence of the system on indoor air quality is analyzed by contrasting the pollutant concentrations of different operation modes of the system.
\end{abstract}

Index Terms - Solar wall system, thermal comfort, indoor air quality, experimental test.

\section{INTRODUCTION}

For rural buildings in severe cold area of China, the long heating period, the low levels of design and construction technology, and the poor energy resource structure, may lead to significant energy consumption in winter [1]. The energy consumption in buildings is becoming increasingly higher, especially in winter when there are both heating and cooking requirements in a rural residential house. However, though the energy input increases, the thermal comfort level and indoor air quality vary little compared with before [2]. On account of poor insulating properties of the envelops and low efficiencies of the heating systems, the indoor air temperature can only be maintained in a range from $5{ }^{\circ} \mathrm{C}$ to $15^{\circ} \mathrm{C}$, on the premise that the energy used for space heating takes up $40 \%$ of the total energy consumption in rural residential buildings [3].

Conventional heating measures, such as Chinese kang, heating stove and indigenous radiator heating system, still play a dominant role in rural building heating field. Most of the energy-using facilities, both heating and kitchen, are mainly reliant on fuel woods, crop stalks or coal, burnt in open fires or stoves to produce heat energy. The energy utilization efficiencies of these systems are only $8-10 \%$. Usually, the indoor pollutants, such as $\mathrm{CO}, \mathrm{CO}_{2}$, particulate matter, $\mathrm{NO}_{\mathrm{x}}$ and $\mathrm{SO}_{2}$, are always far above standard values. Besides, new energy and sustainable energy are rarely utilized

Manuscript received July 9, 2015; revised September 21, 2015. This work was financially supported by a grant from the National Key Technologies R \& D Program of China during the 12th Five-Year Plan Period (No. 2011BAJ08B07).

Tiantian Zhang and Yufei Tan are with the Harbin Institute of Technology, Harbin, China (e-mail: x418298537@163.com, tanyufei2002@163.com). in rural buildings, for instance, only $16.4 \%$ of the investigated houses employ solar energy to produce hot water [4].

Moreover, there is always a contradiction between the heating and ventilation in a rural house in winter. Since the outdoor air temperature is extremely low, if there is an increase in the amount of ventilation, the room air temperature will decrease, thus the heating demand of the room space will increase accordingly [5]. Resolving this conflict becomes a major problem in improving the indoor thermal comfort and air quality.

This paper proposes a solar wall system for rural buildings in cold regions for the purpose of increasing the indoor air temperature as well as improving the indoor air quality. Firstly, the structure and the operation modes of the system are introduced in detail. Then the methods of testing and instrument are detailed. Based on the test, the heating capacity of the solar wall system has been evaluated by investigating the temperature distributions of the solar walls and indoor spaces. Finally, the influence of the system on indoor air quality is analyzed by contrasting the pollutant concentrations of different operation modes of the system.

\section{The Test BuILding AND the Solar Wall System}

The solar wall house is a single-stand building which is seated in north but facing the south. The internal area is 74.5 $\mathrm{m}^{2}$, and the height is $3 \mathrm{~m}$. The external length in the east-west direction is $12 \mathrm{~m}$, and the width in the north-south direction is $8 \mathrm{~m}$. There are 4 rooms, including 2 bedrooms, a kitchen and a sitting room. The external wall is made of solid bricks with a cavity insulating layer and two plaster layers (the total thickness is $500 \mathrm{~mm}$ : $20 \mathrm{~mm}$ internal plaster layer, $240 \mathrm{~mm}$ brick wall layer, $100 \mathrm{~mm}$ insulation layer, $120 \mathrm{~mm}$ brick layer, and $20 \mathrm{~mm}$ external plaster layer). The external windows are all double-glazing windows with the sizes of $2.2 \mathrm{~m} \times 1.8 \mathrm{~m}$ Polystyrene board insulation layers with different thicknesses are added to the roof and ground of the house (for the roof, the thickness of the polystyrene board is $100 \mathrm{~mm}$, and for ground is $50 \mathrm{~mm}$ ). The bedrooms are placed in the south side, and each bedroom is equipped with a Chinese kang for space heating (see Fig. 1).

The solar wall is a glazed transpired collector (GTC) type located on the external surface of the whole south wall with the length of $12 \mathrm{~m}$ and the height of $2.9 \mathrm{~m}$ (see Fig. 2). Except for the window areas, the total area of the black metal plate (also named solar energy collector) is about $18 \mathrm{~m}^{2}$. The solar wall system provides hot air for the south bedrooms. The glass-cover of the solar wall reduces the energy exchange between the solar wall and outdoor air by weakening the 
natural convection and radiation heat transfer. Three fresh air inlets (the sizes are $20 \mathrm{~cm} \times 8 \mathrm{~cm}$ ) are placed at the bottom of the cavity. An air supply outlet $(20 \mathrm{~cm} \times 20 \mathrm{~cm})$ is placed on the ceiling of each bedroom. A return air inlet $(20 \mathrm{~cm} \times 20 \mathrm{~cm})$ is also placed on the external wall of each bedroom. The hot air from the solar wall cavity is distributed to the bedrooms by circular ducts with the diameter of $100 \mathrm{~mm}$. The power source of the air flow is provided by an air fan located in each bedroom.

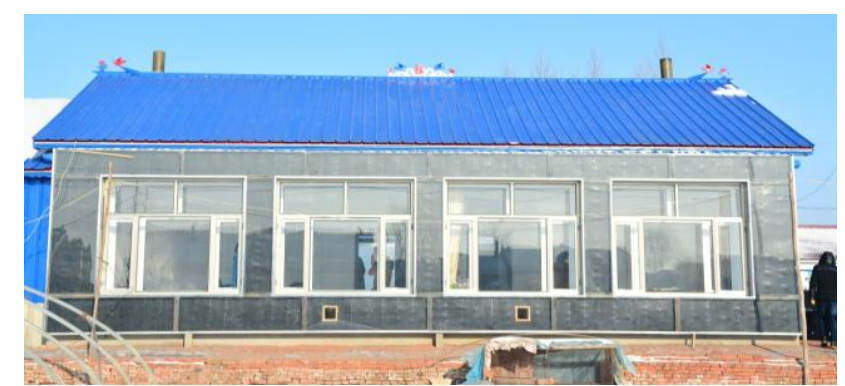

Fig. 1. The appearance of the solar wall house.

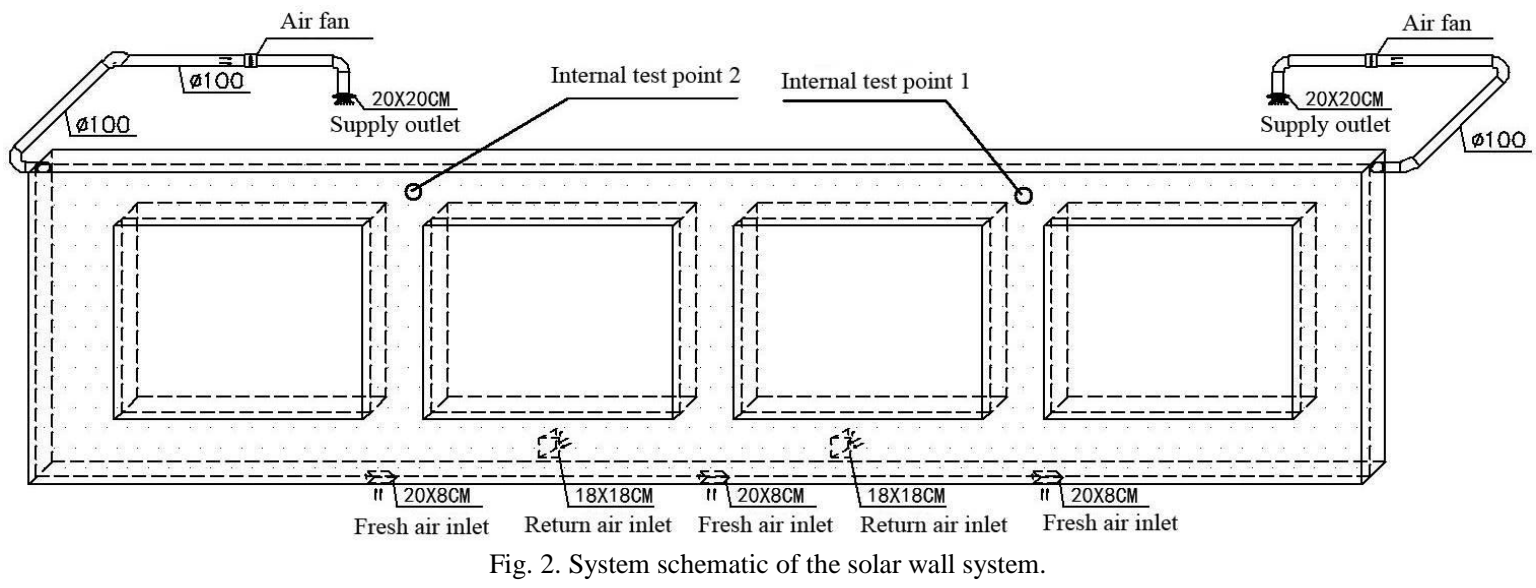

The transpired absorber plate is constructed from metal plate with uniform-distributed holes, which is perforated and covered with selective coating. Each of the uniform-distributed holes on the absorber plate has a diameter of $1 \sim 2 \mathrm{~mm}$. The transpired absorber plate is mounted out 150 $\mathrm{mm}$ from the back plate, and the distance between the absorber plate and the glazing is $150 \mathrm{~mm}$ [6]. Fan draws the outdoor air, or the recirculated air (indoor air), or the mixture of them into the cavity between the glazing and the absorber plate, and then through the transpired absorber plate into the cavity between the transpired absorber plate and the back plate, and at last into the space that need to be heated through air duct. With the promotion of the solar energy absorbed by the metal plate, air is heated when it is drawn through the small holes on the absorber plate. At nighttime, the air inlet and the fan are closed to form an enclosed cavity in the solar wall structure. The heat loss of the external wall is absorbed by the internal air of the enclosed cavity, which offers an air insulation layer for the external envelops.

In summer, the outer cavityis opened, the transpired absorber plate absorbs the solar energy instead of the external walls in a common envelop system, and heats the internal air of the cavity. The air moves from the bottom to the top of the cavity which generates an air exchange between the cavity and the out ambient under the buoyancy results from the temperature difference of the internal air and ambient air. The heat gain of the solar wall system is released to the ambient by the air movement, thus a heating insulation effect is achieved.

Four running modes can be achieved in winter by the solar wall system [7]:

- Full fresh air mode: In this mode, one or more fresh air inlets are opened, while all return air inlets in the bedrooms are closed. The outdoor air is sent into the indoor space after being heated by the transpired absorber plate. The ventilation effect is the biggest in this mode.

- Mixture mode: According to different ventilation demands, one or more fresh air inlets are opened, while corresponding return air inlet in the bedrooms is also opened. The mixture of the fresh air and return air is sent into the indoor space after being heated. The drive force is the combination of the buoyancy and air fans.

- Full return air mode: When the indoor air quality satisfies daily life demands, all fresh air inlets are closed, while all return air inlets are opened. The recalculated return air is sent back to the room space after being heated. In this mode, the heating effect is the biggest.

- Off mode: All air inlet and outlets are closed to form an enclosed cavity in the solar wall structure. The air gap in the enclosed system is served as an air insulation layer for the external envelops.

In summer, the running method of the system is totally different. All return air inlets and all air fans are closed, while all the fresh air inlets and the outlets at the top of cavity 1 are opened. The air exchanges between the internal cavity and the outdoor. In this mode, the heat gain of the external wall in summer daytime can be reduced, thus the indoor air temperature is decreased.

During the test period in winter, there was one Chinese kang in each of the bedroom. The sizes of the kang are $4.6 \mathrm{~m}$ in length, $2.1 \mathrm{~m}$ in width, and $0.6 \mathrm{~m}$ in height. The total surface heating area is about $9.66 \mathrm{~m}^{2}$. The Chinese kangs are the main heating facilities in the house, while the solar wall is served as a supplement heating system and the main ventilation facility.

\section{Test Purpose AND MEASURING Instruments}

The performance tests consist of thermal performance test of the solar wall and the indoor air quality test. Based on the tests, the heating effectiveness of the solar wall hot-air system 
and the improvement on indoor air quality can be investigated.

The testing parameters of the solar wall system includes: solar radiation intensity, outdoor air temperature, supply air temperature, return air temperature, air velocities at refresh air inlet, return air inlet and air supply outlet; the indoor air items includes the concentrations of carbon dioxide $\left(\mathrm{CO}_{2}\right)$, carbon monoxide $(\mathrm{CO})$ and inhalable particulate matters (PM2.5 and PM10). The measuring instruments needed in the tests are listed in Table I.

TABLE I: TEST INSTRUMENTS

\begin{tabular}{|c|c|}
\hline Test items & Test instruments \\
\hline $\begin{array}{l}\text { Indoor and outdoor } \\
\text { temperatures }\end{array}$ & Temperature and humidity data collector \\
\hline Concentrations of & Indoor air quality monitor \\
\hline PM2.5, PM10, CO, $\mathrm{CO}_{2}$ & (Precision: $\pm 3.0 \%$, resolution: $1 \mathrm{ppm}$ ) \\
\hline $\begin{array}{c}\text { Thermal performance of } \\
\text { building envelops }\end{array}$ & $\begin{array}{c}\text { FLUKE thermal infrared imager(operating } \\
\text { temperature:-20 } 250{ }^{\circ} \mathrm{C} \text {; sensitivity }<0.1 \\
{ }^{\circ} \mathrm{C} \text { ) }\end{array}$ \\
\hline $\begin{array}{c}\text { Surface temperatures of } \\
\text { the solar wall }\end{array}$ & copper-constantan thermocouples \\
\hline Surface heat flux & Heat flux sensor \\
\hline Sizes of the building & laser range finder \\
\hline
\end{tabular}

The tests on the four running modes of the solar wall system were processed on Feb. $2^{\text {nd }}, 2015$. The full return air mode was tested from 10:30 AM to11:30 AM; the full fresh air mode was tested from 11:30 AM to13:00 PM; the off mode was tested from 13:30 PM to15:00 PM; the mixture mode was tested from 15:30 PM to16:00 PM. And a continuous test of the solar wall system on the supply air temperature and indoor air temperature was conducted on Feb. $3^{\text {rd }}$.

\section{RESULTS AND DisCUSSIONS}

\section{A. Relationship between Solar Radiation Intensity and Internal Air Temperature}

The variation curve of the solar radiation intensity and the internal temperature curves are two test points are illustrated in Fig. 3.

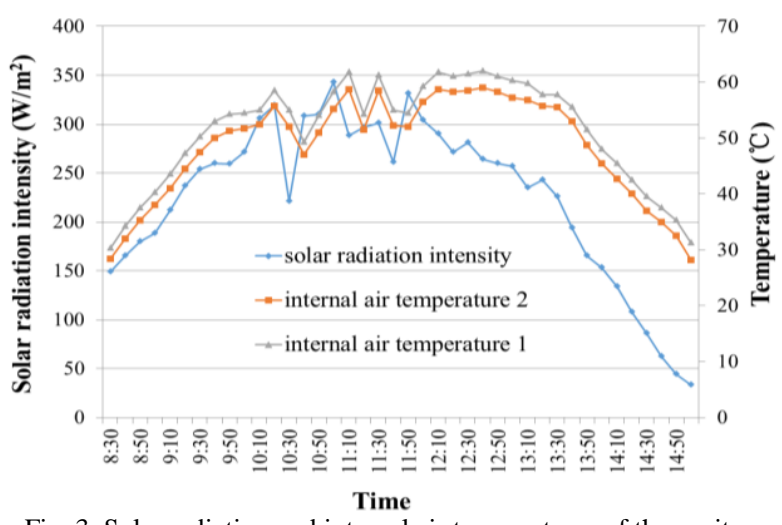

Fig. 3. Solar radiation and internal air temperatures of the cavity.

Test point 1 was located in the external wall of the master bedroom; while point 2 was positioned at the extra bedroom side. The indoor air temperature of the master bedroom is higher, as the Chinese kang in it was heated twice a day since it is the main activity space of the residents. That's the reason why the internal air temperature at point 1 is higher than that of the test point 2 . The difference is about $2{ }^{\circ} \mathrm{C}$ as shown in the above figure.

\section{B. The Supply Air Temperature and the Heat Capacity of Different Running Modes}

The supply air temperatures under different running modes of the solar wall system tested on Feb. $2^{\text {nd }}$ is presented in Table II.

Based on the measured data and extra air velocity data, the heating capacity of the system under different running modes can be obtained according to the following equation:

$$
P=\sum_{i=1}^{2} G_{s, i} \cdot\left(T_{s, i}-T_{w / n}\right) \cdot C
$$

where $P$ is the heating capacity of the system, $\mathrm{W} ; G_{s, i}$ is the air supply volume of room $i, \mathrm{~kg} / \mathrm{s} ; T_{s, i}$ is the supply air temperature of room $i,{ }^{\circ} \mathrm{C} ; T_{w / n}$ is the fresh air temperature or the return air temperature (equals to indoor temperature) or the equivalent temperature of the mixture mode, ${ }^{\circ} \mathrm{C} ; C$ is the specific heat of air, $1.03 \times 10^{3} \mathrm{~J} /\left(\mathrm{kg} \cdot{ }^{\circ} \mathrm{C}\right)$. The calculation results are shown in Table III.

The biggest heating capacity appeared in the mixture mode, the value is $12.26 \mathrm{~kW}$; the full return air mode has a smaller heating capacity to be $10.37 \mathrm{~kW}$; even when the solar wall worked in a full fresh air mode, the heating capacity was still $7.33 \mathrm{~kW}$. Thus, the solar wall system has an excellent heating capacity, as the supply air temperature is high and stable, which ensures a thermal stability of the indoor space.

\begin{tabular}{lcc}
\multicolumn{2}{c}{ TABLE II: SUPPLY AIR TEMPERATURES UNDER DIFFERENT MODES } \\
\hline \hline Running mode & Supply air temperature 1 Supply air temperature 2 \\
\hline Full return air mode & $47.3{ }^{\circ} \mathrm{C}$ & $45.6{ }^{\circ} \mathrm{C}$ \\
Full fresh air mode & $46.3^{\circ} \mathrm{C}$ & $39{ }^{\circ} \mathrm{C}$ \\
Mixture mode & $43.7^{\circ} \mathrm{C}$ & $37.8{ }^{\circ} \mathrm{C}$ \\
\hline \hline
\end{tabular}

TABLE III: HEATING CAPACITIES UNDER DIFFERENT RUNNING MODES

\begin{tabular}{llcc}
\hline \hline Heat capacity $(\mathrm{W})$ & Room 1 & Room 2 & Sum \\
\hline Full return air mode & 5166.72 & 5206.19 & 10372.91 \\
Full fresh air mode & 5093.28 & 2240.11 & 7333.39 \\
Mixture mode & 6176.03 & 6085.83 & 12261.86 \\
\hline \hline
\end{tabular}

\section{The Supply Air Temperature and the Bedroom} Temperatures in a Typical Winter Day

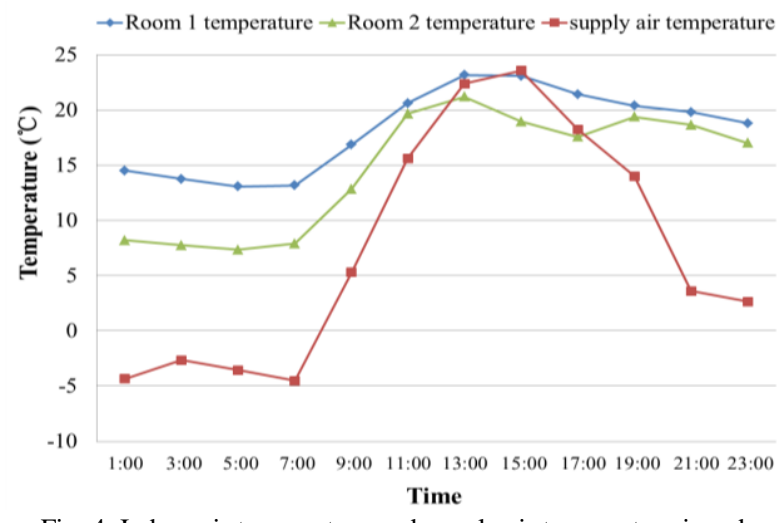

Fig. 4. Indoor air temperature and supply air temperature in a day. 
Fig. 4 illustrates the daily changes of the bedroom temperatures and the supply air temperature. Seen from the figure, the master bedroom has a higher air temperature compared with the extra bedroom. The changing tendencies of the room temperatures and the supply air temperature are the same. The highest temperatures occur at 13:00. Using the solar wall system and the Chinese kang, the master room temperature can be maintained at a comfort level.

\section{Indoor Air Quality Improvement}

Fig. 5 and Fig. 6 show the test results of indoor contaminant concentrations. In the test, the off mode, the full return air mode, the full fresh air mode and the mixture mode of the solar wall system was tested in turn.

Seen from the figures, the concentrations of the indoor inhalable particulate matters are constant with that of the $\mathrm{CO}$, since the pollution sources of these matters are all fuel combustion. When the solar wall converted into the full return air mode, the concentrations of particulate matters didn't change much; but it decreased a lot when the full fresh air mode was switched on; and it continued to decline in the mixture mode. The variation of $\mathrm{CO}$ had the similar changing tendency. The only difference was that the $\mathrm{CO}$ content had a reduction when the running mode changed from off mode to full return air mode. The $\mathrm{CO}_{2}$ concentration was impacted seriously by the activity of residents. When the mode changed from full return air mode to full fresh air mode, the $\mathrm{CO}_{2}$ content decreased significantly, indicating that the full fresh air mode has a great capacity in ventilation. When the mixture mode was on, the $\mathrm{CO}_{2}$ content grew a little, which implies that the mixture has a weaker ventilation capacity compared with the full fresh air mode.

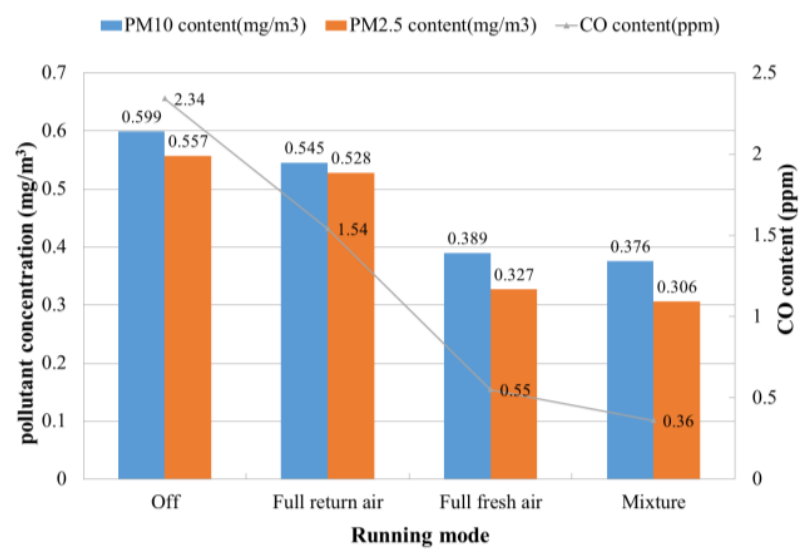

Fig. 5. Concentrations of PM10 and PM2.5.

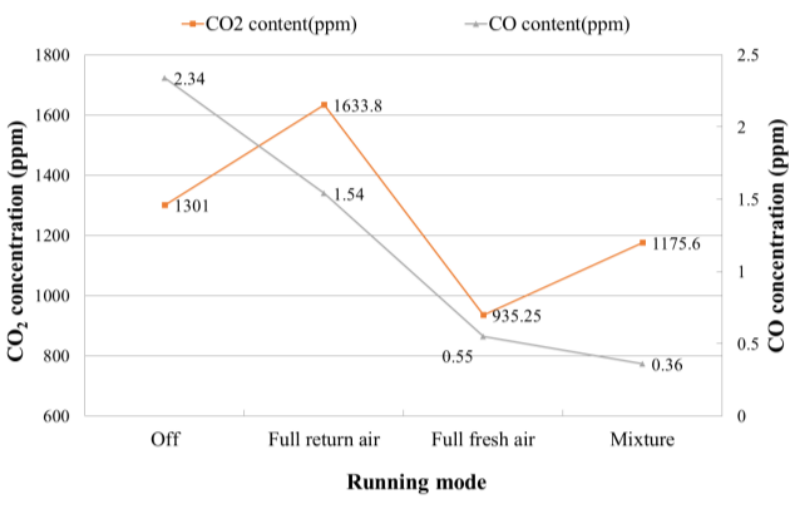

Fig. 6. Concentrations of $\mathrm{CO}$ and $\mathrm{CO}_{2}$.
Table IV illustrates the standard values of indoor air pollutants of a heating room according to IAQS2012 (indoor air quality standard).

TABLE IV: STANDARD VALUES OF INDOOR AIR POLLUTANTS

\begin{tabular}{ccccc}
\hline \hline Category & $\mathrm{CO}$ & $\mathrm{CO}_{2}$ & $\mathrm{PM} 2.5$ & $\mathrm{PM} 10$ \\
\hline unit & {$[\mathrm{ppm}]$} & {$[\mathrm{ppm}]$} & {$\left[\mathrm{mg} / \mathrm{m}^{3}\right]$} & {$\left[\mathrm{mg} / \mathrm{m}^{3}\right]$} \\
standard value & 8 & 1000 & 0.075 & 0.15 \\
\hline \hline
\end{tabular}

Compare the test values to the standard values, when the Chinese kang works, the $\mathrm{CO}_{2}$ content, the PM2.5 and PM10 contents are all above the standards. When the solar wall system starts to work in a full fresh air mode or a mixture mode, the $\mathrm{CO}_{2}$ content can be reduced below the standard value; and the PM2.5 and PM10 contents can be significantly decreased. Due to the excessive utilization of crop stalks, the particulate matters of outdoor air are also above the standards. Thus the solar wall system could not reduce the indoor particulate matter concentrations to a standard level. The solar wall system solves the conflicts between heating and ventilation in rural residential buildings.

\section{CONCLUSION}

The solar wall system solves the conflicts between heating and ventilation in rural residential buildings. The implementation of this system not only ensures the indoor air thermal comfort, but also reduces the indoor pollutant concentrations and increases the indoor air quality. Four running modes can be achieved by the solar wall system in winter: The mixture mode has the biggest heating capacity of $12.26 \mathrm{~kW}$; the full return air mode has a smaller heating capacity to be $10.37 \mathrm{~kW}$; the heating capacity of the full fresh air mode was still $7.33 \mathrm{~kW}$. When the solar wall system works in a full fresh air mode or a mixture mode, the $\mathrm{CO}_{2}$ content can be reduced below the standard value; and the PM2.5 and PM10 contents can be significantly decreased. This wall system also improves the insulation performance of the external envelops by reducing the heat loss in south external walls, and thus reducing the heating load of a rural residential house.

\section{REFERENCES}

[1] C. Liu, "Research on indoor air quality at rural residential house in northeast," M.S. thesis, Harbin Engineering University, Heilongjiang Province, China, 2007.

[2] R. Sun, J. Lv, and S. Ren, "Investigation on energy con-sumption of rural residential housing in northeast area," Building Energy \& Environment, vol. 4, pp. 45-48, April 2011.

[3] H. Jin, H. Zhao, and X. Wang, "Research on the indoor thermal comfort environment of rural housing in winter in super-cold region," Journal of Harbin Institute of Technology, vol, 38, pp. 2108-2111, July 2006.

[4] T. Zhang, Y. Tan, \& X. Zhang, "Current situation of energy and indoor environment in rural buildings of northeast China," Applied Mechanics and Materials, vol, 522-524, pp. 1756-1759, October 2014.

[5] K. Naghman, "A review on wind driven ventilation tech-niques," Energy and Buildings, vol, 40, pp. 1586-1604, August 2008.

[6] L. Gao, H. Bai, and S. Mao, "Potential application of glazed transpired collectors to space heating in cold climates," Energy Conversion and Management, vol, 77, pp. 690-699, May 2014.

[7] L. Gao, H. Bai, and X. Fang, "Experimental study of a building-integrated solar air heating system in cold climate of China," Energy and Buildings, vol. 65, pp. 359-367, February 2013. 


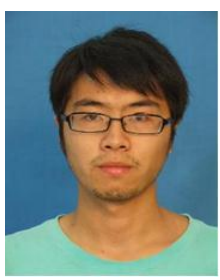

Tiantian Zhang was born on December 4, 1987 in Jingzhou, China. He received his bachelor and master's degree in Harbin Institute of Technology. Now he is a Ph.D. student in HIT. His research interests focus on heat transfer, fluid mechanics, thermodynamics, solar energy, HVAC systems, gas supplying, renewable and sustainable energy technologies in buildings.

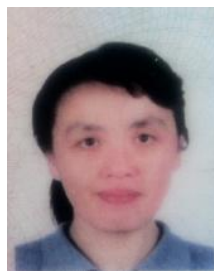

Yufei Tan was born in Harbin, China in 1962. She is now a professor of the School of Municipal and Environmental Engineering, Harbin Institute of Technology, Harbin, China. Her research interests include heat transfer, fluid mechanics, thermodynamics, building energy efficiency, heating ventilation, air conditioning system simulation, and control. 